Article

\title{
Unraveling Toluene Conversion during the Liquid Phase Hydrogenation of Cyclohexene (in Toluene) with Rh Hybrid Catalysts
}

\author{
Mónica Rufete-Beneite and M. Carmen Román-Martínez *(D) \\ Department of Inorganic Chemistry (Faculty of Sciences) and Materials Institute, University of Alicante, E-03080 \\ Alicante, Spain; monica_rufete@hotmail.com \\ * Correspondence: mcroman@ua.es; Tel.: +34-965903975
}

Received: 30 October 2019; Accepted: 17 November 2019; Published: 20 November 2019

\begin{abstract}
Monitoring hydrogen consumption has allowed studying the progress of the liquid phase hydrogenation of cyclohexene in toluene with Rh SILP (supported ionic liquid phase) catalysts prepared by the immobilization of the $\left[\{\mathrm{RhCl}(\mathrm{cod})\}_{2}\right]$ complex on different carbon materials. An excess of hydrogen consumption with respect to the required amount for cyclohexene hydrogenation was registered and related with the solvent (toluene) hydrogenation. The study carried out led to unraveling the extent of toluene hydrogenation and to determining if the rate of this reaction is affected by the properties of the carbon material used as support. The results revealed that the Rh SILP catalysts we prepared showed acceptable toluene conversion, with $100 \%$ selectivity to the total hydrogenated product, and that the effect of the carbon support is the same as for cyclohexene hydrogenation.
\end{abstract}

Keywords: $\left[\{\mathrm{RhCl}(\mathrm{cod})\}_{2}\right]$ complex; SILP catalysts; hydrogen consumption; toluene hydrogenation; cyclohexene hydrogenation

\section{Introduction}

Toluene is a solvent commonly used in several catalytic processes. Examples of its use in the hydroformylation and hydrogenation of olefins can be found in the following references [1-7]. The purpose of most of these research works is to study the transformation of the target substrate into the desired products, usually in relation with the catalysts' properties and the reaction variables. The potentially occurring minor process of solvent hydrogenation remains often unobserved, and it is not taken into account, although it could affect the processes efficiencies. Thus, most studies dealing with hydrogenation reactions in toluene, among them those indicated above [1-7], do not mention the possibility of toluene hydrogenation. This is, likely, because the relatively mild reaction conditions used allow considering negligible the hydrogenation of an aromatic compound, and particularly, toluene as it is much more difficult to hydrogenate than other aromatics, such as naphthalene [8].

Cyclohexene hydrogenation in toluene using SILP (supported ionic liquid phase) catalysts based on carbon materials and the $\left[\{\mathrm{RhCl}(\mathrm{cod})\}_{2}\right]$ complex (chloro(1,5-cyclooctadiene) rhodium(I) dimer, abbreviated as RhCOD) was reported in a previous work [9], which was focused on studying the effect of the carbon support properties on the catalysts' performances. The SILP methodology consists in the immobilization of homogeneous catalysts on solid supports by mean of a solution of the active species in an ionic liquid (IL) that is deposited on their surface [10-14]. This system is a solid heterogeneous catalyst, but the active sites are molecular species able to act as homogeneous catalysts, and thus, it combines the advantages of both, homogeneous and heterogeneous catalysis. Because of that it can be regarded as a hybrid catalyst [10-12,15]. 
Ionic liquids are being broadly used in the field of catalysis as they can either, act as solvents, constitute SILP systems, or take part of other systems formed by metal nanoparticles and ionic liquids. A recent review shows the achievements of this last type of catalyst in arene hydrogenation [16].

In the aforementioned previous work [9], activity data on the hydrogenation of cyclohexene in toluene ( $5 \%$ vol cyclohexene $(\mathrm{CH})$ in toluene, $333 \mathrm{~K}, 10$ bar $\mathrm{H}_{2}, 5 \mathrm{~h}$ ) were mainly obtained by GC analysis of the solution resulting after reaction. In some experiments, the reaction progress was monitored by the continuous measurement of hydrogen consumption, and a certain excess of consumed hydrogen with respect to the amount required for the actual cyclohexene conversion was detected. Such an observation led us to consider that toluene hydrogenation could also be taking place, and because of that, it was considered interesting to perform a thorough analysis of the whole set of hydrogen consumption versus time curves in order to study, in more detail, this side process.

Besides, toluene hydrogenation is a relevant reaction to both the petrochemical and fine chemical industries [17], and it is a representative compound to study the hydrogenation of aromatics. Important industrial catalysts for the hydrogenation of aromatics, and in particular for toluene hydrogenation, are sulfided $\mathrm{Ni}-\mathrm{W} / \mathrm{Al}_{2} \mathrm{O}_{3}$ catalysts [17]. Thus, many research works are focused on Ni catalysts, using more acidic oxide supports $\left(\mathrm{SiO}_{2}-\mathrm{Al}_{2} \mathrm{O}_{3}, \mathrm{TiO}_{2}\right.$, zeolites) or some modification with other elements [17-20]. However, in all these cases the catalysts have a high metal loading, usually above $20 \%$, and the reaction conditions involve temperatures and pressures usually above $200{ }^{\circ} \mathrm{C}$ and $20 \mathrm{bar}$, respectively. With the purpose of exploring alternative, and maybe more convenient catalysts, it was considered interesting to determine the capabilities of the $\left[\{\mathrm{RhCl}(\operatorname{cod})\}_{2}\right]$ SILP catalysts investigated in this study for such a reaction.

\section{Results and Discussion}

\subsection{Summary of the Supports Characterization Data}

The $\mathrm{N}_{2}$ adsorption isotherms of carbons KA and GeA are type I according to the IUPAC classification, typical of microporous materials, while those obtained for samples SA and T are type I+IV, characteristic of solids with micro and mesoporosity [21] (Figure S1, Supplementary Material). The TPD (temperature programmed desorption) profiles of these samples (Figure S2, Supplementary Material) reveal important differences between them regarding their surface chemistry. The determined textural and chemical parameters were previously reported [9] and are collected in Table S1 (Supplementary Material), where it can be seen that the carbon materials used as supports have a quite different porosity and surface chemistry, both in terms of amount and type of surface oxygen groups.

\subsection{Cyclohexene Hydrogenation in Toluene with Homogeneous and Biphasic Systems}

Figure 1 shows the hydrogen consumption versus time curves recorded during the catalytic tests carried out with the homogeneous catalyst and the biphasic system. It can be observed that the hydrogen consumption steadily increases in both cases. Considering the molar stoichiometry for cyclohexene hydrogenation $\left(1: 1, \mathrm{H}_{2}: \mathrm{CH}\right), 120.6 \mathrm{~cm}^{3}$ is the volume of hydrogen required for a $100 \%$ substrate conversion. The data of Figure 1 indicate that hydrogen is consumed in excess with respect to the amount mentioned, and thus, it can be considered that toluene is also being hydrogenated. 


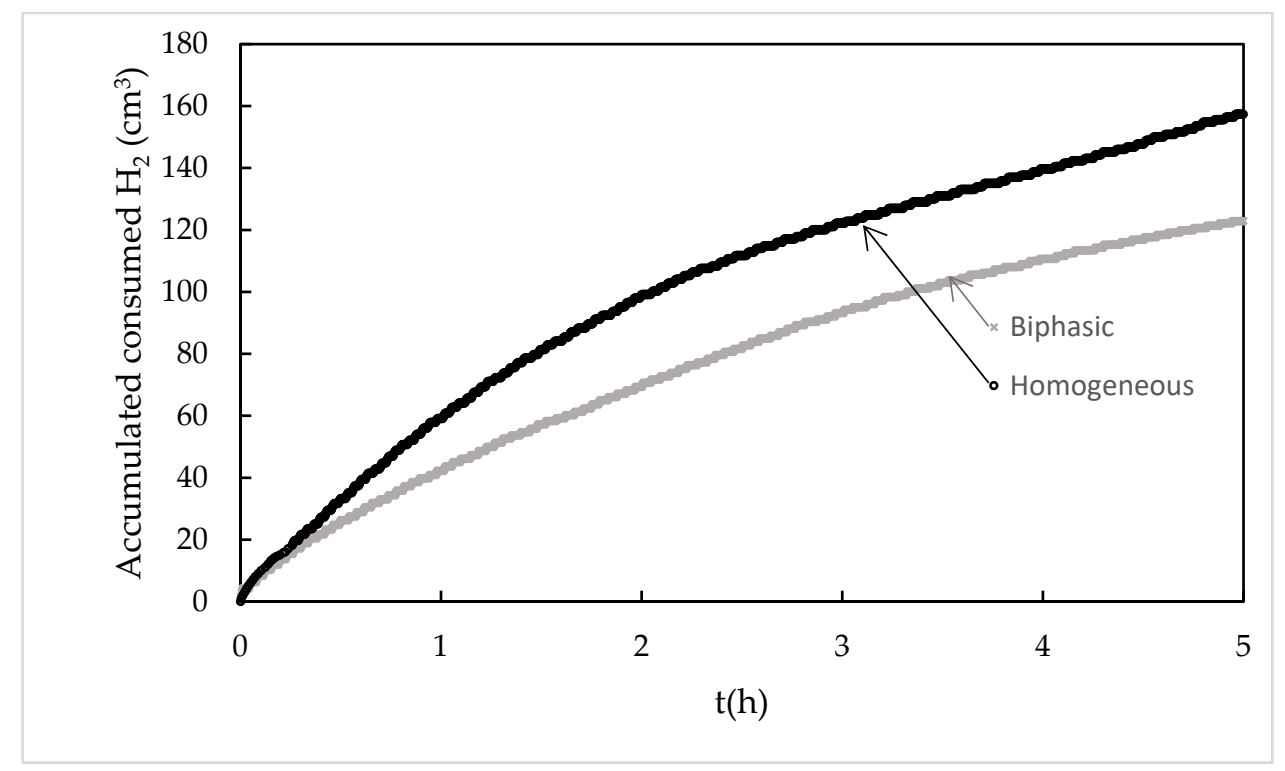

Figure 1. Hydrogen consumption versus time during $\mathrm{CH}$ hydrogenation in toluene $(5 \%$ volume $\mathrm{CH}$ in toluene, $333 \mathrm{~K}, 10$ bar $\mathrm{H}_{2}$ ) with homogenous and biphasic systems.

Table 1 collects data on the amount of hydrogen consumed at $5 \mathrm{~h}$; cyclohexene conversion at the same time, determined by gas chromatography; and the calculated amount of hydrogen required to achieve such a cyclohexene conversion.

Table 1. Hydrogen consumption, $\mathrm{CH}$ conversion and $\mathrm{H}_{2}$ consumption calculated for the $\mathrm{CH}$ conversion measured ( $5 \%$ vol $\mathrm{CH}$ in toluene, $333 \mathrm{~K}, 10$ bar $\mathrm{H}_{2}, 5 \mathrm{~h}$ ).

\begin{tabular}{ccccc}
\hline Catalyst & $\mathbf{H}_{\mathbf{2} \text { cons }}\left(\mathbf{c m}^{\mathbf{3}}\right)^{\mathbf{a}}$ & $\mathbf{C H}$ conv $(\%)$ & $\mathbf{H}_{\mathbf{2}}$ for $\mathbf{C H}_{\text {conv }}\left(\mathbf{c m}^{\mathbf{3}}\right)^{\mathbf{c}}$ & $\mathbf{r}_{\mathbf{0}}\left(\mathbf{m}^{\mathbf{3}} \mathbf{h}^{-\mathbf{1}}\right)^{\mathbf{d}}$ \\
\hline Homogeneous & 142.4 & 98.4 & 118.7 & 27.1 \\
Biphasic & 122.8 & 98.1 & 118.3 & 22.8 \\
\hline
\end{tabular}

${ }^{\mathrm{a}} \mathrm{At} \mathrm{t}=5 \mathrm{~h} .{ }^{\mathrm{b}}$ Cyclohexene $(\mathrm{CH})$ conversion determined by gas chromatography. ${ }^{\mathrm{c}} \mathrm{H}_{2}$ amount calculated to be required for the $\mathrm{CH}$ conversion determined by GC. ${ }^{\mathrm{d}}$ Initial reaction rate calculated as the initial slope (up to $0.5 \mathrm{~h}$ ) of the curves shown in Figure 1.

Cyclohexene conversion at $5 \mathrm{~h}$ is above $98 \%$ for both the homogeneous and the biphasic systems. The amount of hydrogen consumed in excess with respect to the amount needed for such a conversion (23.7 and $4.5 \mathrm{~cm}^{3}$ in the homogeneous and biphasic systems, respectively) should be attributed to toluene hydrogenation. Thus, according to these results, toluene conversion in the homogeneous system is higher than in the biphasic one $(0.36 \%$ versus $0.07 \%)$, which can be explained by the more effective contact between the substrate and the Rh complex in the first case.

The initial reaction rate has been estimated by means of the initial slope (up to $0.5 \mathrm{~h}$ ) of the curves shown in Figure 1 and the calculated data are included in Table 2.

\subsection{Cyclohexene Hydrogenation in Toluene with RhCOD SILP Catalysts}

Table 2 (column 1) shows the amount of hydrogen consumed at $5 \mathrm{~h}$ determined from the $\mathrm{H}_{2}$ consumption versus time curves obtained in the catalytic tests performed with the Rh catalysts. Figure 2 shows, as an example, the hydrogen consumption versus time curve obtained with catalyst SA20-RhCOD. 
Table 2. $\mathrm{H}_{2}$ consumption and conversion data ( $5 \%$ vol $\mathrm{CH}$ in toluene, $333 \mathrm{~K}, 10$ bar $\left.\mathrm{H}_{2}, 5 \mathrm{~h}\right)$.

\begin{tabular}{|c|c|c|c|c|c|c|c|}
\hline & 1 & 2 & 3 & 4 & 5 & 6 & 7 \\
\hline Catalyst & $\mathrm{H}_{2}$ cons $\left(\mathrm{cm}^{3}\right)^{\mathrm{a}}$ & $\underset{(\%)^{\mathrm{b}}}{\mathrm{CH}_{\text {conv }}(\mathrm{GC})}$ & $\begin{array}{l}\mathrm{H}_{2} \text { for } \mathrm{CH}_{\text {conv }} \\
\left(\mathrm{cm}^{3}\right)^{\mathrm{c}}\end{array}$ & $\begin{array}{c}\text { Tol }_{\text {conv }} \text { from } \\
\mathrm{H}_{2} \text { excess (\%) } \\
\underset{\mathrm{d}}{ }(\%)\end{array}$ & $\underset{(\%)}{T o 1_{\text {conv }}(G C)}$ & $\begin{array}{c}\mathrm{mol} \mathrm{Tol} / \mathrm{mol} \\
\mathrm{CH}\end{array}$ & $r_{0}\left(m^{3} h^{-1}\right)^{f}$ \\
\hline KA20-RhCOD & 117.9 & 52.9 & 61.3 & 0.9 & 0.9 & 0.3 & 24.4 \\
\hline GeA20-RhCOD & 193.7 & 92.8 & 111.9 & 1. & 1.4 & 0.3 & 42.6 \\
\hline SA20-RhCOD & 225.9 & 100.0 & 120.6 & 1.6 & 1.7 & 0.3 & 109.2 \\
\hline T20-RhCOD & 212.8 & 100.0 & 120.6 & 1.4 & 1.5 & 0.3 & 38.6 \\
\hline KA-RhCOD & 63.5 & 16.3 & 19.6 & 0.7 & 0.8 & 0.9 & 13.0 \\
\hline
\end{tabular}

${ }^{a}$ At $t=5 \mathrm{~h} .{ }^{b}$ Cyclohexane conversion determined by gas chromatography [9]. ${ }^{c} \mathrm{H}_{2}$ required for the $\mathrm{CH}$ conversion.

${ }^{d} \mathrm{H}_{2}$ excess: total hydrogen consumed minus hydrogen required for $\mathrm{CH}$ hydrogenation. ${ }^{\text {e }}$ Toluene conversion determined by gas chromatography. ${ }^{\mathrm{f}}$ Initial reaction rate calculated as the initial slope (up to $0.5 \mathrm{~h}$ ) of the $\mathrm{H}_{2}$ consumption curves.

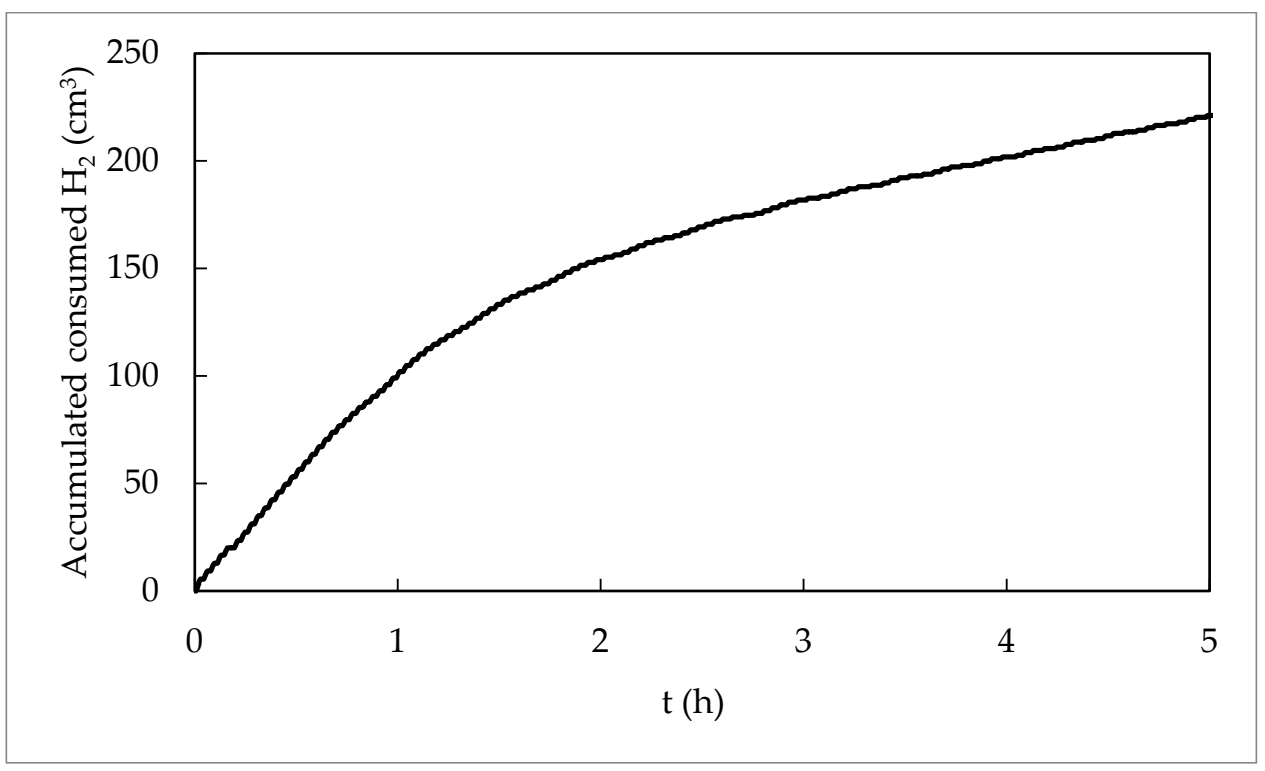

Figure 2. $\mathrm{H}_{2}$ consumption versus time during $\mathrm{CH}$ hydrogenation in toluene with catalyst $\mathrm{SA} 20-\mathrm{RhCOD}$ ( $5 \%$ vol $\mathrm{CH}$ in toluene, $333 \mathrm{~K}, 10$ bar $\mathrm{H}_{2}$ ).

Cyclohexene conversion at $5 \mathrm{~h}$ determined by gas chromatography (data previously reported [9]) is also presented in Table 2 (column 2) along with the amount of hydrogen consumed for such a conversion assuming the 1:1 molar stoichiometry of the $\mathrm{CH}$ hydrogenation reaction (column 3 ). These data show that in all cases, the amount of hydrogen consumed is clearly higher than that required for the cyclohexene conversion measured, and as commented above, the hydrogenation of toluene should be assumed to be occurring.

In order to study such a reaction independently, catalyst SA20-RhCOD was used in a $10 \mathrm{~h}$ catalytic test in the same conditions but without adding cyclohexene to the reaction media. The hydrogen consumption we recorded versus time is depicted in Figure 3, where it can be observed that the hydrogen consumption proceeds quite linearly with time. 


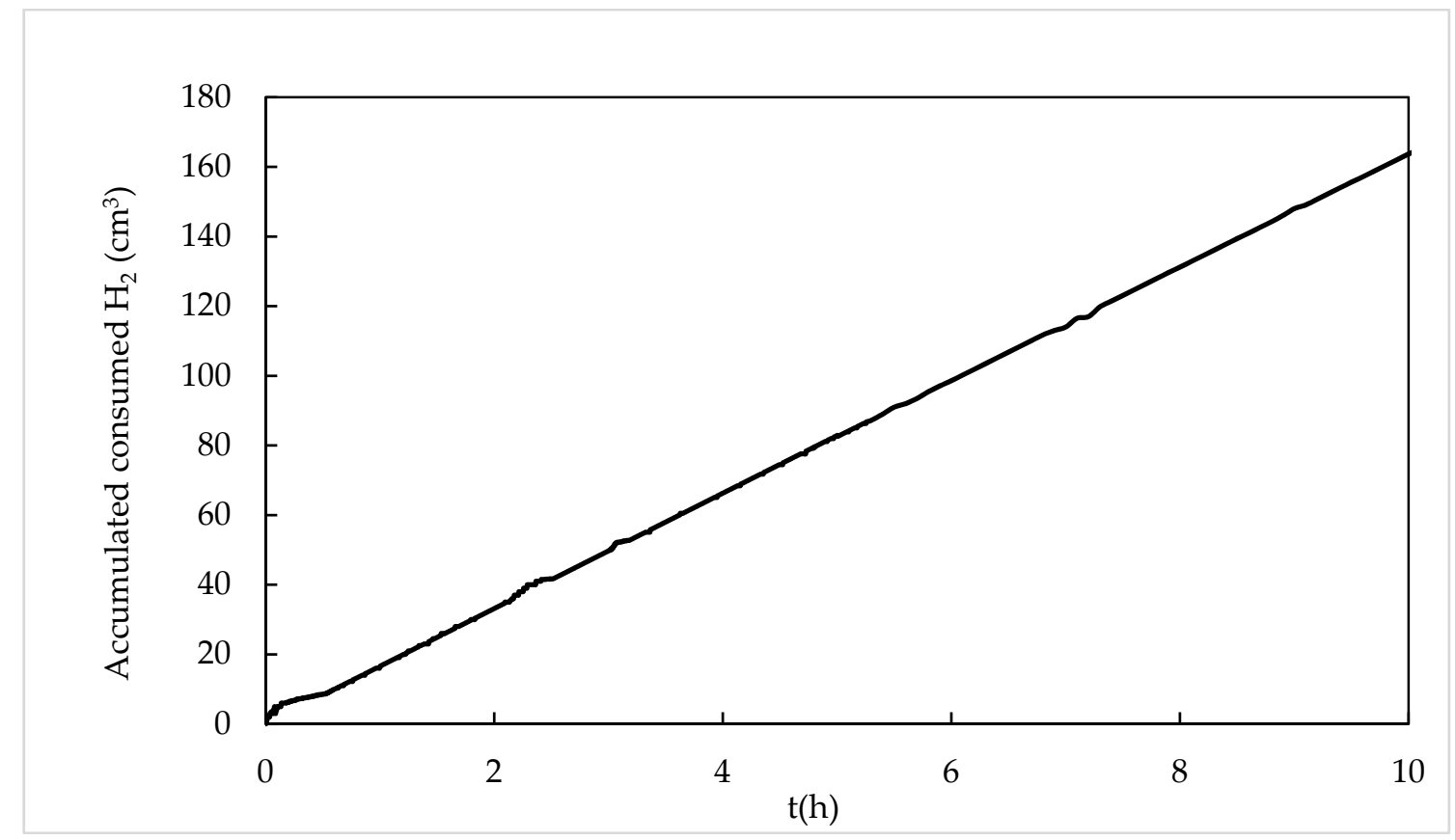

Figure 3. $\mathrm{H}_{2}$ consumption versus time in the hydrogenation of toluene with catalyst SA20-RhCOD (333 K, 10 bar $\left.\mathrm{H}_{2}\right)$.

The reaction solution was analyzed by gas chromatography, and methylcyclohexane was the only product observed. Quantification of this product allowed determining that after $10 \mathrm{~h}$ reaction time, toluene conversion was $2.30 \%$, which corresponds to 0.0020 mol converted toluene. On the other hand, considering that the amount of hydrogen consumed in $10 \mathrm{~h}\left(165.57 \mathrm{~cm}^{3}\right.$, see Figure 3$)$ is used to hydrogenate toluene to methylcyclohexane, the toluene conversion would be $2.04 \%$. Comparison of these two conversion values indicates that there is a good agreement between the results obtained by $\mathrm{H}_{2}$ consumption and by GC analysis of the solution, supporting the reliability of the measurements done with the device developed by the research group to monitor the reaction by means of the $\mathrm{H}_{2}$ consumption (see Section 3.3).

As reported in the previous work [9] (and shown in the Supplementary Material), Rh leaching is very low in all SILP catalysts, less than $0.7 \%$ (Table S2), and XPS results (Table S3) have shown that Rh in the used catalysts remains in the original electronic state (that is, no reduction takes place upon use), even after three consecutive reaction runs.

The activity of the SA20-RhCOD catalyst for toluene hydrogenation is in line with that reported for SCILL catalysts (solid catalysts with ionic liquid layer) in which dendrimer encapsulated Ru nanoparticles supported on silica are coated with an ionic liquid layer [22]. The catalysts, tested in the liquid phase hydrogenation of toluene at $383 \mathrm{~K}$ and $30 \mathrm{bar} \mathrm{H}_{2}$, show reaction rate values that range from $0.5 \cdot 10^{8}$ to $2.0 \cdot 10^{8}\left(\mathrm{~mol}_{\mathrm{tol}}\right) \cdot\left(\mathrm{mol}_{\mathrm{Ru}}\right)^{-1} \mathrm{~m}^{-3} \mathrm{~h}^{-1}$ depending on the IL used. The toluene conversion of catalyst SA20-RhCOD in $10 \mathrm{~h}$ corresponds to a reaction rate of $1.37 \cdot 10^{8}\left(\mathrm{~mol}_{\mathrm{tol}}\right) \cdot\left(\mathrm{mol}_{\mathrm{Rh}}\right)^{-1} \mathrm{~m}^{-3} \mathrm{~h}^{-1}$ (and to a turn over frequency (TOF) of $0.0190 \mathrm{~s}^{-1}$ ) which was achieved in significantly milder conditions, $333 \mathrm{~K}$ and 10 bar $\mathrm{H}_{2}$ than those reported in [22]. This catalyst is also clearly more active for toluene hydrogenation than other catalysts based on Rh nanoparticles in ionic liquid [23]. In this case, the authors report TON (turnover number) values (calculated as mol of consumed $\mathrm{H}_{2}$ per mol of introduced $\mathrm{Rh}$ ) of 255 and 300 (under reaction conditions of $353 \mathrm{~K}, 40 \mathrm{bar}, 15 \mathrm{~h}$ ), while the analogous value obtained for the SA20-RhCOD catalyst was 2550. Additionally, in the work of Suppino et al. [24], in which Pt, Pd and Ru catalysts supported on alumina have been developed for the hydrogenation of toluene at $373 \mathrm{~K}$ and $50 \mathrm{bar}$, the reported reaction rates are lower than those reported in the present work. The maximum reaction rate values reported by these authors are about $3 \cdot 10^{7}\left(\mathrm{~mol}_{\mathrm{tol}}\right) \cdot\left(\mathrm{mol}_{\mathrm{M}}\right)^{-1} \mathrm{~m}^{-3} \mathrm{~h}^{-1}$. 
Once assured that the SILP catalysts are able to hydrogenate toluene at $333 \mathrm{~K}$ and 10 bar $\mathrm{H}_{2}$, the hydrogen consumed in excess during the cyclohexene hydrogenation tests has been attributed definitively to toluene hydrogenation. This allows calculating toluene (Tol) conversion in each test. Table 2 (column 4) shows toluene conversion calculated in this way. It can be seen that toluene conversion in $5 \mathrm{~h}$ with the SILP catalysts ranges from $0.9 \%$ to $1.6 \%$ and it is bit lower with the KA-RhCOD sample (the one prepared without ionic liquid). Besides, a careful analysis of the GC data led to the determination of methylcyclohexane and to calculate also toluene conversion from these data (Table 2, column 5). Both values (columns 4 and 5) are coherent, and thus, it can be concluded that the hydrogen consumption curves are very useful in order to determine the extent of toluene hydrogenation when it is used as a solvent.

To compare cyclohexene $(\mathrm{CH})$ and toluene (Tol) hydrogenation activities of each catalyst, the molar ratio of converted $\mathrm{CH}$ to converted Tol has been calculated and included in Table 2 (column 6). It can be observed that the four Rh SILP catalysts are significantly more active for $\mathrm{CH}$ than for Tol hydrogenation (activity for $\mathrm{CH}$ hydrogenation is about three times the activity for Tol hydrogenation). However, catalyst KA-RhCOD, prepared without ionic liquid, that is less active than the SILP catalysts in both hydrogenation reactions, is, in relative terms, more active for toluene hydrogenation, bringing the activity for both reactions closer. This result reveals the importance of the ionic liquid to keeping a suitable state of the active species. On the other hand, and as previously reported [9], the Rh SILP catalysts prepared with supports that have micro and mesopores are more active for $\mathrm{CH}$ hydrogenation than the one prepared with the essentially microporous carbon support (carbon KA). The equal molar ratio of converted Tol to converted $\mathrm{CH}$ (column 6, Table 2) obtained in this study for all the SILP catalysts means that this applies also for the hydrogenation of toluene. That is, the textural properties of the carbon material used as supports have a similar effect in the activity of the Rh SILP catalysts for the hydrogenation of cyclohexene and the hydrogenation of toluene.

The initial reaction rate, estimated by the initial slope (up to $0.5 \mathrm{~h}$ ) of the $\mathrm{H}_{2}$ consumption curves, is also included in Table 2 (column 7).

Table 3 shows the calculated TOF and TON data corresponding to hydrogenation of cyclohexene and toluene in the hydrogenation tests of cyclohexene in toluene.

Table 3. TOF (turn over frequency) and TON (turnover number) values in the hydrogenation of cyclohexene and toluene $\left(5 \%\right.$ vol $\mathrm{CH}$ in toluene, $333 \mathrm{~K}, 10$ bar $\left.\mathrm{H}_{2}\right)$, determined after $5 \mathrm{~h}$ of reacting.

\begin{tabular}{ccccc}
\hline & \multicolumn{2}{c}{ CH Hydrogenation } & \multicolumn{2}{c}{ Tol Hydrogenation } \\
\hline Catalyst & TOF $\left(\mathbf{s}^{-\mathbf{1}}\right)$ & TON & TOF (s $\left.\mathbf{s}^{\mathbf{1}}\right)$ & TON \\
\hline KA20-RhCOD & 0.050 & 900 & 0.016 & 288 \\
GeA20-RhCOD & 0.087 & 1566 & 0.023 & 414 \\
SA20-RhCOD & 0.094 & 1692 & 0.029 & 522 \\
T20-RhCOD & 0.094 & 1692 & 0.025 & 450 \\
KA-RhCOD & 0.015 & 270 & 0.013 & 234 \\
\hline
\end{tabular}

These results can be compared with those reported by Pawelec et al. [8] that studied the simultaneous hydrogenation of toluene and naphthalene in the presence of dibenzothiophene using Pt and Pd catalysts supported on zeolites. The process was studied in a continuous down flow catalytic reactor at $448 \mathrm{~K}$ and 50 bar. Most of the catalysts studied by these authors show TOF values (calculated from the reported reaction rates) that range from 0.01 and $0.06 \mathrm{~s}^{-1}$. In spite of the differences in the process performance, it can be concluded that the activity of the catalysts studied in the present work for toluene hydrogenation (in the presence of other substrates) is reasonably high, mainly considering the mild operation conditions. 


\subsection{Kinetics of the Hydrogenation of Cyclohexene in Toluene}

Assuming that toluene hydrogenation occurs in a similar way when it is pure and mixed with cyclohexene, the hydrogen consumption registered in the test carried out with pure toluene using sample SA20-RhCOD (Figure 3) was subtracted from analogous data determined with the 5 vol\% solution of $\mathrm{CH}$ in Tol (Figure 2). The resulting plot, shown in Figure 4, should represent the kinetic curve of the independent $\mathrm{CH}$ hydrogenation reaction. This is a typical kinetic curve similar to the one found previously for cyclohexene hydrogenation with homogeneous $\mathrm{Rh}$ and $\mathrm{Pd}$ amine complexes [25]. Thus, this analysis could indicate that the catalytic behavior of the RhCOD complex heterogenized by the SILP methodology resembles that of the one being used in homogeneous phase, which supports the hybrid character (homogeneous/heterogeneous) of these catalysts.

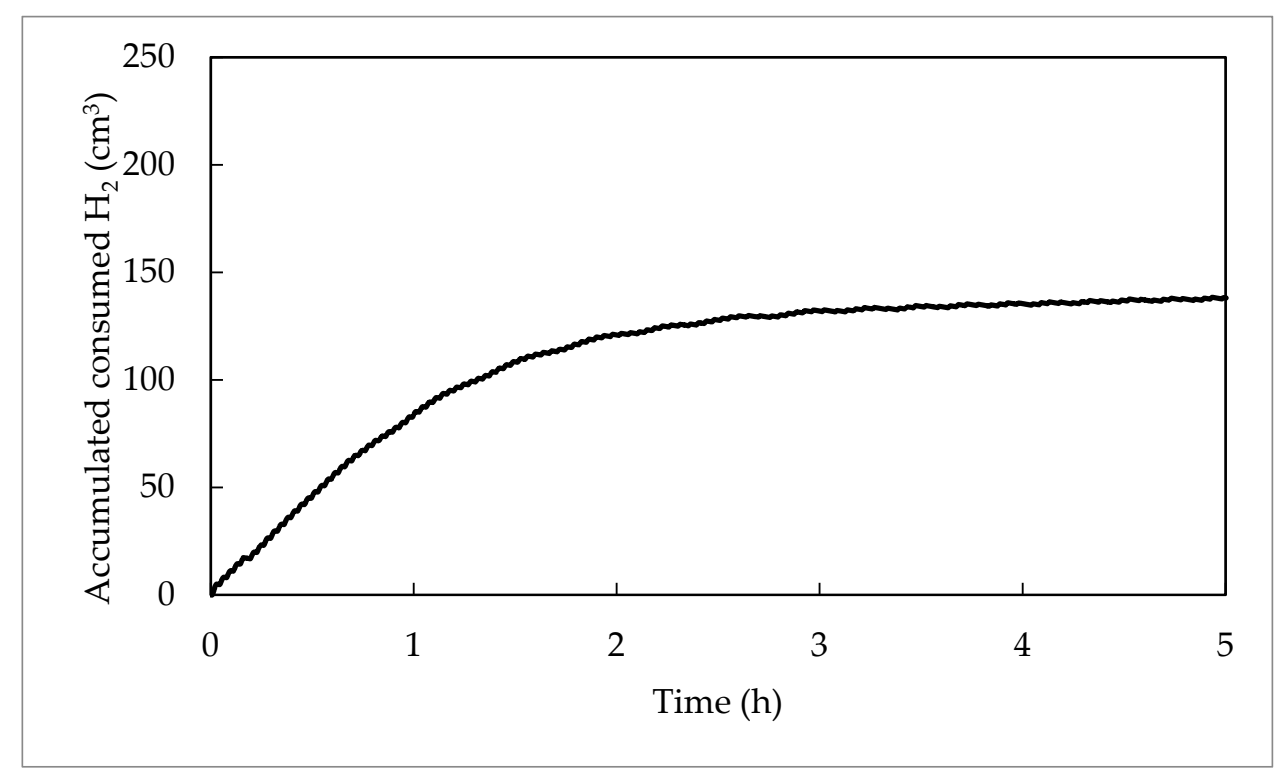

Figure 4. $\mathrm{H}_{2}$ consumption versus time curve for catalyst SA20-RhCOD obtained by subtracting the $\mathrm{H}_{2}$ consumption versus time curve determined for pure toluene hydrogenation (Figure 3) from the $\mathrm{H}_{2}$ consumption versus time curve measured for the hydrogenation of cyclohexene in toluene $(333 \mathrm{~K}, 10$ bar $\mathrm{H}_{2}$ ) shown in Figure 2.

Additionally, the $\mathrm{H}_{2}$ consumption versus time curve of Figure 4 shows that the reaction time for a high $\mathrm{CH}$ conversion can be reduced. It can be seen that the maximum $\mathrm{CH}$ conversion was reached in about $3 \mathrm{~h}$. Thus, the TOF value reported in Table 3 for this sample can be recalculated, considering a 3 instead $5 \mathrm{~h}$ reaction time, what brings about a much higher value, $0.157 \mathrm{~s}^{-1}$. Furthermore, if the TOF is calculated for an $80 \% \mathrm{CH}$ conversion, which is achieved at $1.5 \mathrm{~h}$ according to Figure 4, the noticeably high value of $0.250 \mathrm{~s}^{-1}$ is determined.

In summary, monitoring the hydrogenation of $\mathrm{CH}$ in toluene by the $\mathrm{H}_{2}$ consumption occurring during the process has allowed: to determine that toluene hydrogenation also takes place, to show the independent hydrogenation of $\mathrm{CH}$, and to state that the Rh SILP catalysts reported in this work are reasonably active for toluene hydrogenation. Thus, they could be an interesting option for carrying out the hydrogenation of such an aromatic compound.

\section{Materials and Methods}

\subsection{Supports}

The SILP catalysts were prepared using as support, the following commercial carbon materials [9]: GeA-activated carbon of spherical morphology prepared by Gun-ei Chemical Industry (Takasaki-shi, Gunma, Japan,) from a phenolic resin. The average diameter of the spheres is $150 \mu \mathrm{m}$. 
KA—activated carbon of spherical morphology produced by Kureha Corporation (Takasaki-shi, Gunma, Japan) from petroleum pitch. The average diameter of the spheres is $780 \mu \mathrm{m}$.

T-carbon black T-10157 produced by Columbian Chemical Company (Centerville, LA, USA).

SA-powder activated carbon named SA-30 produced by MeadWestvaco (Richmond, VA, USA).

They were characterized by gas adsorption $\left(\mathrm{N}_{2}\right.$ at $77 \mathrm{~K}$ and $\mathrm{CO}_{2}$ at $\left.273 \mathrm{~K}\right)$ to determine the textural properties, and by temperature programmed desorption (TPD) experiments to assess the surface chemistry, as indicated in [9].

\subsection{Catalysts' Preparations and Characterizations}

The SILP catalysts were prepared using the ionic liquid (IL) 1-butyl-3-methyl imidazolium hexafluorophosphate $\left([\mathrm{bmim}]\left[\mathrm{PF}_{6}\right]\right)$ and the $\left[\{\mathrm{RhCl}(\mathrm{cod})\}_{2}\right]$ complex (chloro(1,5-cyclooctadiene) rhodium(I) dimer (abbreviated as RhCOD)). Preparation of catalysts with $20 \mathrm{wt} \%$ IL and $1 \mathrm{wt} \%$ Rh loading was carried out inside a Schlenk apparatus as follows: the appropriate amounts of ionic liquid and RhCOD and $2 \mathrm{~cm}^{3}$ anhydrous acetone, were added under Ar atmosphere to $0.5 \mathrm{~g}$ of the support (previously outgassed under vacuum at $423 \mathrm{~K}$ for $5 \mathrm{~h}$ ). The mixture was stirred until the sample had a dry appearance. The catalysts generic name is SUP20-RhCOD, where SUP is in each case the support name (see above, indicated in Section 3.1) and 20 refers to the weight percentage of ionic liquid in the sample. A catalyst without ionic liquid was prepared using carbon KA as support by the same procedure but skipping the addition of the $[\mathrm{bmim}]\left[\mathrm{PF}_{6}\right]$ compound. This catalyst was named KA-RhCOD.

The amount of Rh in fresh and used catalysts was determined by ICP, after decomposition of the carbon material by acid treatment as indicated in [9]. Determinations on the fresh catalysts revealed Rh loading between 0.95 and $0.98 \mathrm{wt} \%$. Fresh and used catalysts were analyzed by X-ray photoelectron spectroscopy (XPS) using a VG-Microtech Multilab 3000 apparatus (Thermo Fisher Scientific, Waltham, MA, USA) in order to determine the chemical state of rhodium, and by transmission electron microscopy (TEM) using a JEM-2010 JEOL microscope (JEOL, Akishima, Japan) to obtain information about the samples' morphologies and compositions.

\subsection{Liquid Phase Hydrogenation of Cyclohexene in Toluene}

In a typical test, $30 \mathrm{mg}$ catalyst $(2.9 \mu \mathrm{mol} \mathrm{Rh})$ and $10 \mathrm{~cm}^{3}$ of a $5 \mathrm{vol} \%$ cyclohexene in toluene solution $\left(4 \cdot 9 \cdot 10^{-3} \mathrm{~mol}\right.$ cyclohexene) were introduced in the stainless steel reactor. After closure, a leak test was performed, and then, the system was heated to $333 \mathrm{~K}$ and pressurized with $10 \mathrm{bar}_{2}$. In a reference biphasic system, the catalyst consisted of a solution of $1.5 \mathrm{mg}$ RhCOD in $0.01 \mathrm{~cm}^{3}$ ionic liquid. For a homogeneous phase test, $1.5 \mathrm{mg}$ of RhCOD was dissolved in the substrate solution; $1.5 \mathrm{mg}$ is the amount of $\mathrm{Rh}(\mathrm{COD})$ contained in $30 \mathrm{mg}$ of the hybrid catalysts. The reaction time was $5 \mathrm{~h}$ and its evolution was followed through the hydrogen consumption by means of an experimental device specifically developed for this purpose. It is based on the continuous measurement of the pressure inside the reactor and the automatic activation of a hydrogen feeding system in case the pressure falls below a certain value ( 10 bar in this case). Thus, when the pressure decreases (below 10 bar) due to the reaction progress, a valve automatically opens to feed hydrogen into the reactor until the initial fixed pressure is reached again. A mass flow meter allows registering the amount of hydrogen introduced into the system during the reaction and the data accumulated is the hydrogen consumed. A scheme of the experimental device is shown in Figure 5. 


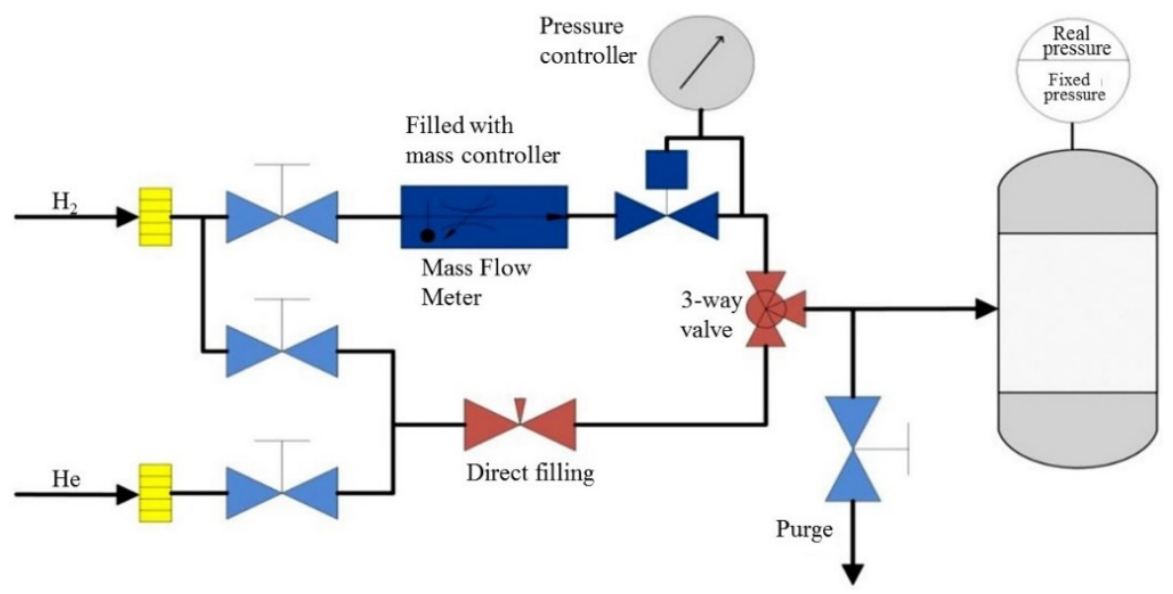

Figure 5. Scheme of the hydrogen consumption monitoring system.

The absence of leaks was tested prior each experiment by filling the system with a certain gas pressure and ensuring that there was not a pressure drop.

On the other hand, the reaction medium was analyzed by gas chromatography (HP6890 Series II with the column HP-1 MethylSiloxane $30 \mathrm{~m} \times 250 \mu \mathrm{m} \times 0.25 \mu \mathrm{m}$, Palo Alto, CA, USA). For the analysis, $150 \mu \mathrm{L}$ of the problem solution was mixed with $250 \mu \mathrm{L}$ acetone and $100 \mu \mathrm{L}$ of a $7285 \mathrm{ppm}$ solution of decane (internal standard) in acetone.

\section{Conclusions}

Following the progress of the hydrogenation of cyclohexene in toluene by hydrogen consumption has allowed unraveling the fact that SILP catalysts are able to hydrogenate toluene in liquid phase (at

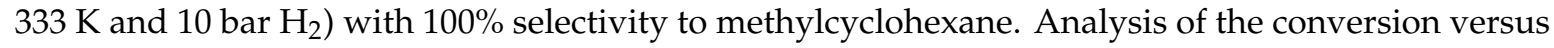
time curves has permitted us to determine the extent of toluene conversion with the studied catalysts. Additionally, such an analysis is useful to unveil the kinetic curve of the independent hydrogenation of cyclohexene in the cyclohexene/toluene reaction media.

$\mathrm{Rh}$ SILP catalysts prepared with carbon materials that have both, micro and mesopores are more active in the hydrogenation of toluene than those prepared with essentially microporous carbon materials. These results are in agreement with the previously reported behavior of these catalysts for cyclohexene hydrogenation.

It must be also pointed out that the prepared carbon based SILP catalysts are active for the hydrogenation of toluene, showing activity values which are comparable with those found in the literature.

Supplementary Materials: The following are available online at http://www.mdpi.com/2073-4344/9/12/973/s1. Figure S1: $\mathrm{N}_{2}$ adsorption isotherms at $77 \mathrm{~K}$ of the carbon materials. Figure S2: TPD profiles $\left(\mathrm{CO}_{2}\right.$ (empty markers) and $\mathrm{CO}$ (filled markers refer to the secondary axis)) of the original carbon materials (experimental conditions: 10 $\mathrm{Kmin}^{-1}$ up to $1273 \mathrm{~K}$ and $100 \mathrm{~cm}^{3} \mathrm{~min}^{-1} \mathrm{He}$ ). Table S1: Main characterization of the carbon materials used as supports: Textural properties and oxygen surface chemistry. Table S2: Rh leaching upon catalysts use ( $5 \mathrm{vol} \%$ cyclohexene in toluene, $333 \mathrm{~K}, 10 \mathrm{bar} \mathrm{H}_{2}, 5 \mathrm{~h}$ ). Table S2: XPS Rh 3d binding energy data of fresh and used catalysts ( 5 vol\% cyclohexene in toluene, $333 \mathrm{~K}, 10$ bar $\mathrm{H}_{2}, 1.5 \mathrm{~h}$ ).

Author Contributions: Conceptualization, M.C.R.-M.; methodology, M.R.-B. and M.C.R.-M.; formal analysis, M.R.-B. and M.C.R.-M.; Investigation, M.R.-B. and M.C.R.-M.; data curation, M.R.-B. and M.C.R.-M.; writing - original draft preparation, M.R.-B. and M.C.R.-M.; writing-review and editing, M.C.R.-M.; supervision, M.C.R.-M.; project administration, M.C.R.-M.; funding acquisition, M.C.R.-M.

Funding: The work was funded by the Spanish Ministry of Science, Innovation and Universities and FEDER, project of reference RTI2018-095291-B-I00, GV/FEDER (PROMETEO/2018/076) and University of Alicante (project VIGROB-136).

Conflicts of Interest: The authors declare no conflict of interest. 


\section{References}

1. Standfest-Hauser, C.M.; Lummerstorfer, T.; Schmid, R.; Hoffmann, H.; Kirchner, K.; Puchberger, M.; Trzeciak, A.M.; Mieczyńska, E.; Tylus, W.; Ziółkowski, J.J. Rhodium Phosphine Complexes Immobilized on Silica as Active Catalysts for 1-Hexene Hydroformylation and Arene Hydrogenation. J. Mol. Catal. A Chem. 2004, 210, 179-187. [CrossRef]

2. Lindner, E.; Mayer, H.A.; Warad, I.; Eichele, K. Supported Organometallic Complexes: Part XXXV. Synthesis, Characterization, and Catalytic Application of a New Family of Diamine(Diphosphine)Ruthenium Complexes. J. Organomet. Chem. 2003, 665, 176-185. [CrossRef]

3. Cagnola, E.A.; Quiroga, M.E.; Liprandi, D.A.; L'Argentière, P.C. Immobilized Rh, Ru, Pd and Ni Complexes as Catalysts in the Hydrogenation of Cyclohexene. Appl. Catal. A Gen. 2004, 274, 205-212. [CrossRef]

4. Sudheesh, N.; Sharma, V.K.; Shukla, R.S.; Jasra, R.V. Investigations on the Kinetics of Hydroformylation of 1-Hexene Using $\mathrm{HRh}(\mathrm{CO})\left(\mathrm{PPh}_{3}\right)_{3}$ Encapsulated Hexagonal Mesoporous Silica as Heterogeneous Catalyst. J. Mol. Catal. A Chem. 2009, 316, 23-29. [CrossRef]

5. Sudheesh, N.; Chaturvedi, A.K.; Shukla, R.S. RhCl(TPPTS) ${ }_{3}$ Encapsulated into the Hexagonal Mesoporous Silica as an Efficient Heterogeneous Catalyst for Hydroformylation of Vinyl Esters. Appl. Catal. A Gen. 2011, 409, 99-105. [CrossRef]

6. Wolfson, A.; Vankelecom, I.F.J.; Jacobs, P.A. Co-Immobilization of Transition-Metal Complexes and Ionic Liquids in a Polymeric Support for Liquid-Phase Hydrogenations. Tetrahedron Lett. 2003, 44, 1195-1198. [CrossRef]

7. Yang, Y.; Deng, C.; Yuan, Y. Characterization and Hydroformylation Performance of Mesoporous MCM-41-Supported Water-Soluble Rh Complex Dissolved in Ionic Liquids. J. Catal. 2005, 232, 108-116. [CrossRef]

8. Pawelec, B.; Mariscal, R.; Navarro, R.M.; Van Bokhorst, S.; Rojas, S. Hydrogenation of Aromatics over Supported Pt-Pd Catalysts. Appl. Catal. 2005, 225, 223-237. [CrossRef]

9. Rufete-Beneite, M.; Román-Martínez, M.C. Support Effects on SILP Hybrid Catalysts Prepared with Carbon Materials and the RhCOD Complex. RSC Adv. 2016, 6, 100976-100983. [CrossRef]

10. Gu, Y.; Li, G. Ionic Liquids-Based Catalysis with Solids: State of the Art. Adv. Synth. Catal. 2009, 351, 817-847. [CrossRef]

11. Riisager, A.; Fehrmann, R.; Haumann, M.; Wasserscheid, P. Supported Ionic Liquids: Versatile Reaction and Separation Media. Top. Catal. 2006, 40, 91-102. [CrossRef]

12. Van Doorslaer, C.; Wahlen, J.; Mertens, P.; Binnemans, K.; De Vos, D. Immobilization of Molecular Catalysts in Supported Ionic Liquid Phases. Dalton Trans. 2010, 39, 8377-8390. [CrossRef] [PubMed]

13. Li, Y.; Dong, Y.; Li, W.; Han, Y.; Zhang, J. Improvement of Imidazolium-Based Ionic Liquids on the Activity of Ruthenium Catalyst for Acetylene Hydrochlorination. Mol. Catal. 2017, 443, 220-227. [CrossRef]

14. Zhang, Q.; Zhang, S.; Deng, Y. Recent Advances in Ionic Liquid Catalysis. Green Chem. 2011, $13,2619$. [CrossRef]

15. Selvam, T.; MacHoke, A.; Schwieger, W. Supported Ionic Liquids on Non-Porous and Porous Inorganic Materials - A Topical Review. Appl. Catal. A Gen. 2012, 445-446, 92-101. [CrossRef]

16. Chacón, G.; Dupont, J. Arene Hydrogenation by Metal Nanoparticles in Ionic Liquids. ChemCatChem 2019, 11, 333-341. [CrossRef]

17. Stanislaus, A.; Barry, H.C. Aromatic Hydrogenation Catalysis: A Review. Catal. Rev. 1994, 36, 75-123. [CrossRef]

18. Rautanen, P.A.; Aittamaa, J.R.; Krause, A.O.I. Solvent Effect in Liquid-Phase Hydrogenation of Toluene. Ind. Eng. Chem. Res. 2000, 39, 4032-4039. [CrossRef]

19. Chu, H.; Li, N.; Niu, L.; Liu, C.; Qiu, M.; Bai, G. Continuous Hydrogenation of Toluene over Sr- and PEG800-Modified Ni/g-AlO 3 Catalysts. Chem. Eng. Technol. 2015, 38, 1585-1590. [CrossRef]

20. Shuwa, S.M.; Jibril, B.Y.; Al-Hajri, R.S. Hydrogenation of Toluene on Ni-Co-Mo Supported Zeolite Catalysts. Niger. J. Technol. 2017, 36, 1114-1123. [CrossRef]

21. Rouquerol, F.; Rouquerol, J.; Sing, K. Adsorption by Powders E Porous Solids_Principles, Methodology and Applications; Academic Press: London, UK, 1999. 
22. Antonels, N.C.; Benjamin Williams, M.; Meijboom, R.; Haumann, M. Well-Defined Dendrimer Encapsulated Ruthenium SCILL Catalysts for Partial Hydrogenation of Toluene in Liquid-Phase. J. Mol. Catal. A Chem. 2016, 421, 156-160. [CrossRef]

23. Léger, B.; Denicourt-Nowicki, A.; Olivier-Bourbigou, H.; Roucoux, A. Imidazolium-Functionalized Bipyridine Derivatives: A Promising Family of Ligands for Catalytical Rh(0) Colloids. Tetrahedron Lett. 2009, 50, 6531-6533. [CrossRef]

24. Suppino, R.S.; Landers, R.; Cobo, A.J.G. Influence of Noble Metals (Pd, Pt) on the Performance of $\mathrm{Ru} / \mathrm{Al}_{2} \mathrm{O}_{3}$ Based Catalysts for Toluene Hydrogenation in Liquid Phase. Appl. Catal. A Gen. 2016, 525, 41-49. [CrossRef]

25. Román-Martínez, M.C.; Díaz-Auñón, J.A.; L'Argentière, P.C.; Salinas-Martínez de Lecea, C. Long-Chain-Amine Metal Complexes as Hydrogenation Catalysts. Heterogenisation on Activated Carbon. Catal. Lett. 2001, 77, 41-46. [CrossRef]

(C) 2019 by the authors. Licensee MDPI, Basel, Switzerland. This article is an open access article distributed under the terms and conditions of the Creative Commons Attribution (CC BY) license (http://creativecommons.org/licenses/by/4.0/). 